\title{
Biocultural Design: Harvesting Manomin with Wabaseemoong Independent Nations
}

\author{
Valeria Kuzivanova ${ }^{1 *}$ and lain J. Davidson-Hunt ${ }^{1}$ \\ ${ }^{1}$ Natural Resources Institute, University of Manitoba, Winnipeg, Manitoba, Canada. \\ *valeriakuzivanova@gmail.com
}

\begin{abstract}
This essay describes how biocultural design (BD) was utilized to develop a manomin (wild rice, Zizania palustris) harvest camp and the prospect of this approach to implement the principles reflected in recent calls for an Ethnobiology 5. In this case, BD brought together knowledge, practices, and innovation within an intentional process of co-design to respond to the specific community aspirations of restoring relationships with manomin. The paper provides an overview of the benefits and challenges of using the practice of BD to re-establish wild rice harvesting. The information presented here is part of a larger initiative to restore manomin habitats, harvest practices, and consumption being undertaken by Wabaseemoong Independent Nations, Northwestern Ontario, Canada.
\end{abstract}

Received September 22, 2016

OPEN ठACCESS

Accepted January 8, 2017

DOI 10.14237/ebl.8.1.2017.794

Keywords Biocultural restoration, Wild rice, Ethnobotany, Anishinaabeg, Canada

Copyright (C) 2017 by the author(s); licensee Society of Ethnobiology. This is an open-access article distributed under the terms of the Creative Commons Attribution-NonCommercial 4.0 International Public License (https://creativecommons.org/licenses/by-nc/4.0), which permits non-commercial use, distribution, and reproduction in any medium, provided the original author and source are credited.

\section{Introduction}

Ethnobiology 5-as described by Nabhan et al. (2011), Wolverton (2013), and Wyndham et al. (2011) -prioritizes applied science, multidisciplinarity, respect for different knowledge systems, support of Indigenous innovation, and cultural practices that increase the resilience of social-ecological systems. It also opens space for forward-looking approaches with a focus on problem-solving, guided by local values and different knowledge systems building upon earlier ideas promoted by Posey et al. (1984) and Beaucage and Taller de Tradición Oral del Cepec (1997). These approaches are biocultural, ecocultural, ecogastronomic, focal, and reciprocal because they recognize the linkages between landscape degradation, damage, and destruction of landscapes and the disappearance of values, knowledge, practices, and beliefs of landscape inhabitants (e.g., Gavin et al. 2015; Higgs 2003; Janzen 1988; Kimmerer 2011; Martinez 2003; Nabhan et al. 2010).

Notable for its absence within the proposal for an Ethnobiology 5, is design, despite having a presence within anthropological responses to the representational crisis (Rabinow et al. 2008). Biocultural design (BD) is rooted in a perspective that local biological materials have potential as resources for meeting aspirations of local communities through design projects that are inclusive of diverse knowledges about, and respectful of local values related to, the materials being utilized (Davidson-Hunt et al. 2012). It signals an intention to co-produce knowledge that addresses contemporary problems that are multidimensional and resists simple solutions using a process which moves from inspiring action to implementing ideas (Buchanan 1992; Davidson-Hunt et al. 2012). $\mathrm{BD}$ also reflects a recent engagement of anthropological texts with design as a movement toward interaction with materials and cultural processes of making other worlds possible (Escobar 2011; Ingold 2013).

Additionally, BD draws upon the idea of biocultural heritage, which includes biological materials, traditional ecological knowledge (TEK), and innovations (Apgar et al. 2011; Gavin et al. 2015; Swiderska 2006). The use of TEK-which is "a cumulative body of knowledge, practice and belief evolving by adaptive processes and handed down through generations by cultural transmission" (Berkes 2012:7) - is an empowering act that allows for the reclamation of biocultural heritage and increases the social acceptability, economic feasibility, and ecological viability of 


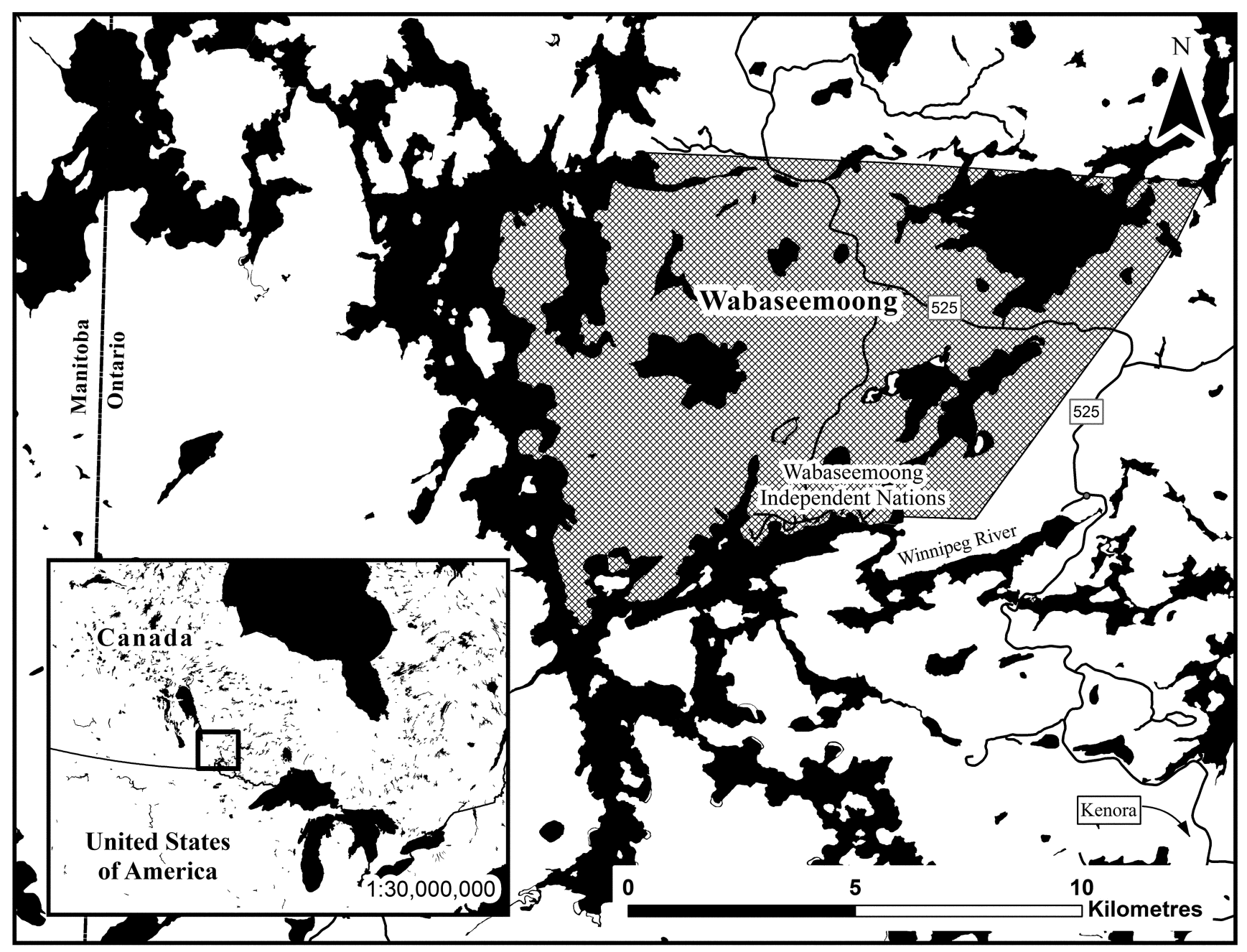

Figure 1 Geographic location of the Wabaseemoong Independent Nations community.

projects. TEK also contributes to "intensely respectful emotional engagement with nature," which is a prerequisite for long-term community involvement with biological materials (Hunn 2014:148). Moreover, TEK includes processes of creativity and innovation as individuals navigate the contemporary environments of their lives, drawing upon their histories and cultural memories linking the past with possible futures (Davidson-Hunt 2003).

$\mathrm{BD}$ is an incipient design practice. It will develop as it is applied in diverse contexts and through such application concepts, and methodologies will be refined as outcomes, benefits, and challenges are evaluated. In this case, $\mathrm{BD}$ provided an approach to support our community colleague who desired a reengagement with the practice of manomin (Zizania palustris) harvesting by the Anishinaabe (Ojibway,
Ojibwa, Saulteaux, Chippewa) people of Wabaseemoong Independent Nations, located in Northwestern Ontario, Canada (Figure 1). This community, like other Anishinaabe communities of the boreal forest, has been harvesting wild rice as a dietary staple and a plant of spiritual, symbolic, and economic significance since before recorded time. In August or September, for several weeks, most community members moved to their wild rice camps for the harvest. Then, they either processed-or finished-manomin to prepare it for consumption, or sold it green (unprocessed) to buyers.

Until the 1900s, Anishinaabe harvesting and finishing had remained mostly subsistence-based and relatively stable. However, the twentieth century brought enormous ecological, socio-cultural, and economic changes that disrupted wild rice harvesting 
and decreased community involvement (Kuzivanova 2016). Residential schools where children lived separately from their families, the industrialization of wild rice production, the loss of land resulting from the establishment of Whiteshell Provincial Park, and the introduction of welfare and other economic opportunities on reserve lands, disrupted the relationships Wabaseemoong Independent Nations members had with manomin. Wild rice habitats were negatively impacted by hydroelectric developments on the Winnipeg River and its principal tributary, the English River, and an increase in hydroelectric power consumption. The disappearance of wild rice harvesting and finishing practices resulted in diminishing knowledge and a shift of values, especially the knowledge and values of the younger generation. This loss is one of the main grievances of Wabaseemoong Independent Nations Elders.

\section{Biocultural Design: An Approach to Biocultural Restoration}

$\mathrm{BD}$ can be thought of as a problem-solving practice comprised of values that guide the selected methodologies. Davidson-Hunt et al. (2012) suggest that the design team should identify values that act as a set of guiding coordinates for the design process. They provide some general coordinates related to the composition of the design team and its operational principles, political support, and other key values. These guiding coordinates are not meant to be prescriptive, but rather provide the team with a way to ensure innovations are consistent with their values. They also allow opportunities for creativity to emerge from the participants, who work toward identifying activities to fulfill their aspirations.

The first step undertaken in Wabaseemoong Independent Nations was to form a design team made up of community members and co-led by $\mathrm{V}$. Kuzivanova and M. McDonald, who was the initiator of the project in the community. Then, the team identified the guiding coordinates for the project as shown in Table 1. These coordinates drew upon the ideas from human-centered design (Brown 2009; IDEO 2009), capability sensitive design (Oosterlaken 2009), and wild design that focuses specifically on biocultural restoration projects (Higgs 2003; Higgs and Hobbs 2010). They also relied on local values, similarly to the values-focused approach described in Reid et al. (2014). While we used BD as an overarching practice of innovation and problem solving, the specific methods-participant observation, inter- views, and biophysical methods-allowed for the collection of data at the early stages of information gathering. This data was then utilized as part of design workshops to generate ideas and prototypes that responded to the initial aspiration of the project.

\section{Biocultural Restoration: Outcomes}

Besides the process of co-design itself, the main project outcomes referred to TEK documentation, site selection, and the involvement of children and young people through the community school (see Kuzivanova 2016 for details). The documentation of TEK at the beginning of the project allowed for the description and comparison of the relationships between Wabaseemoong Independent Nations members and manomin in the past and in the present, as well as identification of cultural and ecological historical reference conditions for the restoration process. The choice and documentation of the sites for restoration efforts was based on historical and biophysical data, as well as site accessibility. The school, as the main partner for the involvement of young people and children, incorporated knowledge about manomin in its formal and informal curricula. The inclusion of this culturally appropriate knowledge contributed not only to the establishment of the missing relationships between community members and wild rice, but also to ongoing efforts of school staff to implement approaches that can transform and decolonize their system of education.

One of the end products of this project was a working prototype for a wild rice camp, which the project participants chose as the main platform for reestablishing relationships between community members and manomin due to its hands-on character and the direct involvement of participants. The wild rice camp took place in the Wabaseemoong Traditional Land Use Area on September 15-18, 2014. Its prototype extensively relied on community residents' TEK, included different traditional elements, took place at the selected site, and allowed for the participation of diverse community members: Elders, Social Services department clients, teachers, and high school students. It also provided opportunities for visiting cultural sites, crossing old portages, and offering tobacco, which is a sacred gift traditionally used in ceremonies. Overall, the camp contributed to restorying of the landscape through resurfacing memories that were shared by Elders with the younger generations and re-encoding manomin values into the culture-an important process of biocultural restora- 


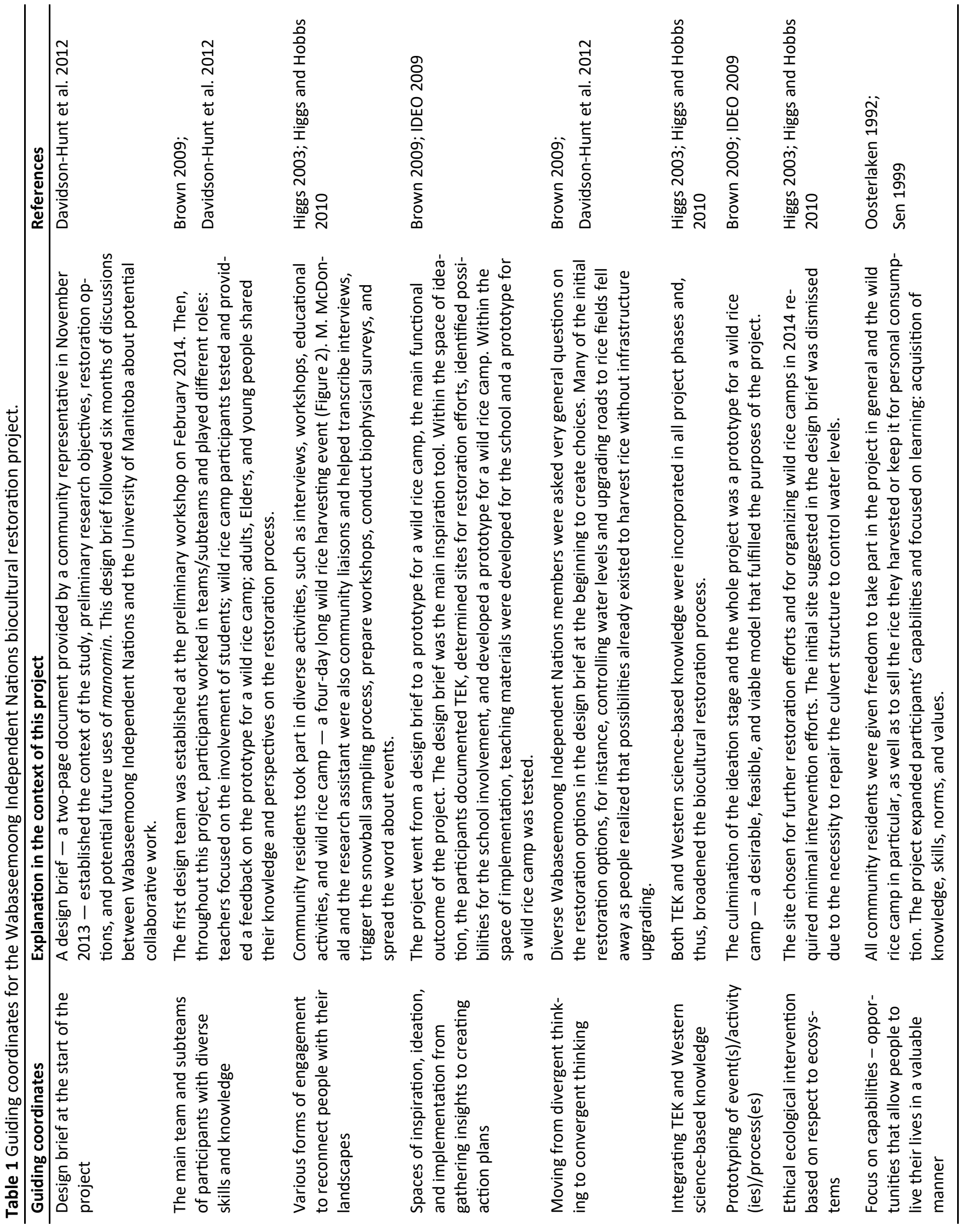


tion (Wabaseemoong Wild Rice Project 2016). One of the Elder male camp participants later explained the importance of this experience:

We talked to each other... It's like we lived in the past. We were kids again. We pictured our parents. I could visualize all the relatives from the community. I could see them and feel the connection... How empowering it is. It is really something.

\section{Reflections on the Approach: Why Biocultural Design?}

A biocultural design approach links an established practice of design with the biological materials and capabilities available to communities to meet their aspirations. Design practice has moved toward multidimensional approaches that recognize that many challenges do not have single solutions but rather are indeterminate and comprise holistic complexes of related elements, which require systemic thinking-known by some as wicked problems (Buchanan 1992). BD incorporates such ideas from design but with a specific focus on how local biological materials can contribute to processes of innovation that systematically include ecological, economic, social, and cultural dimensions. We propose four benefits of using the BD approach for biocultural restoration projects: co-designing in a team, prototyping, the capability approach, and the action component, as well as one major challenge.

First, BD is a process of co-design in a team, which means that the product, service, or the whole system is designed in collaboration with subteams of people who will use it in the future (Burkett 2014). In the Wabaseemoong Independent Nations case, design brought multi-aged community residents and university researchers together. The diverse knowledge, skills, and experience of community members and university researchers increased the amount of available expertise and the possibility of unforeseen outcomes. Community Elders were the main project guides who shared their knowledge about traditional manomin harvesting, finishing, and storage practices, identified the reasons for the disruption of these practices, informed the site selection process, showed how to make traditional equipment for the camp, and retold stories that were included in the educational process. Community teachers shared ideas on how wild rice could be included in the curricula and organized high school students' outing to the ricing site. Young people, who were also viewed as knowl-

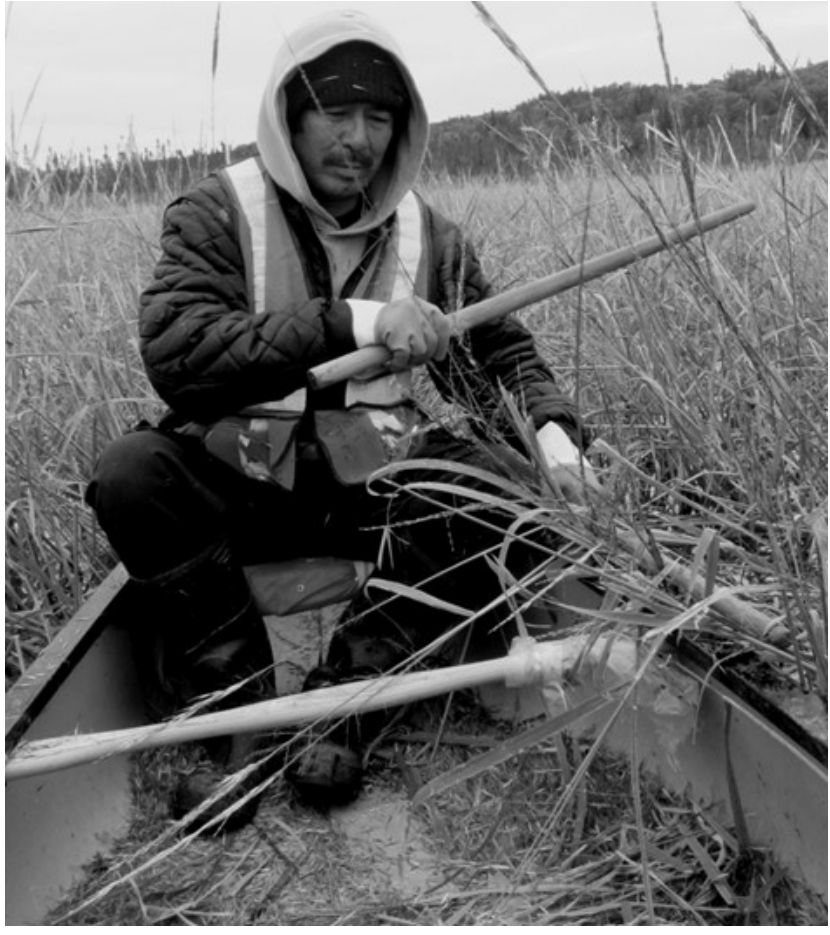

Figure 2 I. Fisher knocking manomin into the canoe, 2014. Photo credit: Valeria Kuzivanova.

edgeable individuals, reflected on the restoration process and the involvement of the students. The main challenge for the co-leads of the design team was to ensure that all points of view, opinions, ideas, and expertise were respected. Respect, as one of the guiding coordinates of the design process, required the co-designers to actively ensure that diverse perspectives were stated and considered at the early workshops during the design and implementation of the manomin harvest camp and as part of the final evaluation.

One more positive characteristic of design lies in the recognition that every idea generated is a potential prototype, which diversifies restoration projects and helps to avoid a rigid technocratic process. After the testing and improvement of prototypes, new prototypes emerge because prototyping inspires new ideas (Brown 2009). As the first wild rice camp in 2014 was considered a prototype, it was adapted and improved in 2015 and 2016 based on the suggestions of the 2014 camp participants. In the future, this prototype may additionally be adapted and applied to other community initiatives targeted at self-determined development and cultural well-being through the awareness of the value of traditional foods, such as 
wild game and blueberries. Besides the wild rice camp, numerous other related prototypes were generated and implemented for educational programs and activities. Some examples are educational posters for science and native language classes, Elder-youth workshops, and a nine-minute video showing the whole process of ricing-wild rice harvesting and finishing-which can be found on the project Facebook page (Wabaseemoong Wild Rice Project 2016).

Additionally, design is a re-affirming and capability-enhancing process. It identifies solutions that build upon existing capabilities (sensu Sen 1999) rather than gaps between what is needed and existing capabilities (Table 1). Design also shifts the focus to appreciative inquiry, which considers people as having gifts and skills, treats organizations as capable, and focuses on the development of worthwhile ideas (Burkett 2014). For example, the facilitation techniques used at the Wabaseemoong Independent Nations design workshops were primarily targeted at setting goals and identifying advantages. As opposed to approaches that highlight what is missing, design expands capabilities and allows building confidence to incrementally address more challenging problems.

Another positive characteristic of $\mathrm{BD}$ is that it changes the dominant discourse of Indigenous peoples as victims to one that can be constructed by participants themselves as doers. Overall, design brings the needed action component to biocultural restoration and translates knowledge into practice by using applied research as part of the design process (Higgs and Hobbs 2010; Wolverton 2013; Wyndham et al. 2011). BD recognizes that cultural processes are the means by which knowledge becomes dynamic and meets contemporary needs by building upon the ecological and cultural endowments of people living upon the lands of their ancestors (Davidson-Hunt et al. 2012). A male Elder and teacher from Wabaseemoong Independent Nations powerfully expressed the idea of the dynamism of knowledge, which contributes to land stewardship:

Hopefully, in the future, students can go not just rice picking, but also participate in other activities and preserve wildlife because it involves everything: the water, the plants, the trees, all that is right there... That's why we need to keep moving and protect this area ...

While $\mathrm{BD}$ can be used to recognize capabilities and catalyze action, it is an approach that requires time to realize the benefits, which is one of the main challenges. Participation allowing for community ownership of project outcomes requires iterative cycles of visioning, gathering information, assessing potential opportunities, deciding upon pathways of action, and evaluating outcomes before implementing a solution. A young male teacher from outside the community, who also participated in the wild rice camp, pointed out this challenge:

Going back and ricing brought tears into the eyes of those who already have experience and memories... I feel that it hasn't necessarily translated to the next generation yet. They don't have this bank of memories and experiences to draw from ... As this happens over years, you start to reclaim those experiences into the culture. That's good and that's momentum. The thing is just carrying forward this momentum to next year.

The leadership provided by diverse community members allowed for such momentum. The camp was undertaken again in 2015 and 2016.

\section{Conclusion}

Ethnobiology 5 has opened a new space for the practice of ethnobiology. We offer this perspective piece not as a critique of Ethnobiology 5 but as an addition of a practice that could provide a new approach for an ethnobiology of the contemporary. While still incipient as a practice, we suggest that design could infuse ethnobiology with a renewed vigor in supporting the co-production of knowledge about biological materials to respond to present challenges of Indigenous and local communities.

\section{Acknowledgments}

We would like to thank community members for their wisdom and hospitality. In spite of their sacred relationship to manomin, they accepted, trusted us, and allowed us to be involved. We would especially like to acknowledge Marvin McDonald, the main community research partner and the lead project co-designer, and his whole family, for being very supportive and caring in both professional and personal capacities. We also thank anonymous reviewers and the EBL editorial team for their constructive comments. This research became possible due to the financial support of the Social Sciences and Humanities Research Council Grants \#890-2011-0113 and \#435-2015-1478, PI Davidson-Hunt, the University of Manitoba, and the 
Government of Manitoba.

\section{Declarations}

Permissions: Research Ethics and Compliance Approval Certificate issued by the Joint-Faculty Research Ethics Board (University of Manitoba).

Sources of Funding: Social Sciences and Humanities Research Council Grants \#890-2011-0113 and \#4352015-1478, PI Davidson-Hunt, the University of Manitoba, and the Government of Manitoba.

Conflicts of Interest. None declared.

\section{References Cited}

Apgar, J. M., J. M. Ataria, and W. J. Allen. 2011. Managing beyond Designations: Supporting Endogenous Processes for Nurturing Biocultural Development. International Journal of Heritage Studies 17:555-570. DOI:10.1080/13527258.2011.618250.

Beaucage, P., and Taller de Tradición oral del Cepec. 1997. Integrating Innovation: The Traditional Nahua Coffee-Orchard (Sierra Norte de Puebla, Mexico). Journal of Ethnobiology 17:45-67.

Berkes, F. 2012. Sacred Ecology, 3rd edition. Routledge, New York, NY.

Brown, T. 2009. Change by Design: How Design Thinking Transforms Organizations and Inspires Innovation. Harper Collins Publishers, New York, NY.

Buchanan, R. 1992. Wicked Problems in Design Thinking. Design Issues 8:5-21.

Burkett, I. 2014. An Introduction to Co-Design [web page]. Available at: http://

www.design4socialinnovation.com.au/wp-content/ uploads/2014/09/An-Introduction-to-Co-Designby-Ingrid-Burkett.pdf. Accessed on December 12, 2015.

Davidson-Hunt, I. J. 2003. Indigenous Lands Management, Cultural Landscapes and Anishinaabe People of Shoal Lake, Northwestern Ontario, Canada. Environments 31:21-41.

Davidson-Hunt, I. J., K. L. Turner, A. T. Pareake Mead, J. Cabrera-Lopez, R. Bolton, C. J. Idrobo, I. Miretski, A. Morrison, and J. P. Robson. 2012. Biocultural Design: A New Conceptual Framework for Sustainable Development in Rural Indigenous and Local Communities. S.A.P.I.EN.S. Surveys and Perspectives Integrating Environment and Society 5:33-45. Available at: http://sapiens.revues.org/1382.
Accessed on December 1, 2013.

Escobar, A. 2011. Sustainability: Design for the Pluriverse. Development 54:137-140.

Gavin, M. C., J. McCarter, A. Mead, F. Berkes, J. R. Stepp, D. Peterson, and R. Tang. 2015. Defining Biocultural Approaches to Conservation. Trends in Ecology and Evolution 30:140-145. DOI:10.1016/ j.tree.2014.12.005.

Higgs, E. S. 2003. Nature by Design: People, Natural Processes, and Ecological Restoration. Massachusetts Institute of Technology Press, Cambridge, MA.

Higgs, E. S., and R. J. Hobbs. 2010. Wild Design: Principles to Guide Interventions in Protected Areas. In Beyond Naturalness: Rethinking Parks and Wilderness Stewardship in an Era of Rapid Change, edited by D. N. Cole and L. Yung, pp. 234-251. Island Press, Washington, DC.

Hunn, E. 2014. To Know Them Is to Love Them. Ethnobiology Letters 5:146-150. DOI:10.14237/ ebl.5.2014.297.

IDEO. 2009. Human-Centered Design Toolkit, $2^{\text {nd }}$ edition. IDEO, San Francisco, CA.

Ingold, T. 2013. Making: Anthropology, Archaeology, Art and Architecture. Routledge, London, United Kingdom, and New York, NY.

Janzen, D. H. 1988. Tropical Ecological and Biocultural Restoration. Science 239:243-244.

Kimmerer, R. 2011. Restoration and Reciprocity: The Contributions of Traditional Ecological Knowledge. In Human Dimensions of Ecological Restoration: Integrating Science, Nature, and Culture, edited by D. Egan, E. E. Hjerpe, and J. Abrams, pp. 257-276. Island Press, Washington, DC.

Kuzivanova, V. 2016. Restoring Manomin (Wild Rice): A Case Study with Wabaseemoong Independent Nations. Unpublished Master's Thesis, Natural Resources Institute, University of Manitoba, Winnipeg, MB, Canada. Available at: https:// umanitoba.ca/institutes/natural_resources/pdf/ theses/Kuzivanova, \%20Valeria.MRNM\% 202015.pdf. Accessed on June 20, 2016.

Martinez, D. 2003. Protected Areas, Indigenous Peoples, and the Western Idea of Nature. Ecological Restoration 21:247-250. Available at: https:// www.ser.org/docs/default-document-library/ protected-areas-indigenous-peoples-and-the-western 
-idea-of-nature.pdf?sfvrsn=0. Accessed on April 20, 2014.

Nabhan, G. P., D. Walker, and A. M. Moreno. 2010. Biocultural and Ecogastronomic Restoration: The Renewing America's Food Traditions Alliance. Ecological Restoration 28:266-279. Available at: http:// www.albc-usa.org/RAFT/images/Resources/ Biocultural_and_Ecogastronomic_Restoration.pdf. Accessed on March 25, 2014.

Nabhan, G. P., F. Wyndham, and D. Lepofsky. 2011. Ethnobiology for a Diverse World: Ethnobiology Emerging from a Time of Crisis. Journal of Ethnobiology 31:172-175. DOI:10.2993/0278-0771-31.2.172.

Oosterlaken, I. 2009. Design for Development: A Capability Approach. Design Issues 25:91-102.

Posey, D. A., J. Frechione, J. Eddins, and L. F. da Silva. 1984. Ethnoecology as Applied Anthropology in Amazonian Development. Human Organization 43:95-107.

Rabinow, P., G. E. Marcus, J. D. Faubion, and T. Rees. 2008. Designs for an Anthropology of the Contemporary. Duke University Press, Durham, NC.

Reid, M. G., C. Hamilton, S. K. Reid, W. Trousdale, C. Hill, N. Turner, C. R. Picard, C. Lamontagne, and H. D. Matthews. 2014. Indigenous Climate Change Adaptation Planning Using a ValuesFocused Approach: A Case Study with the Gitga'at Nation. Journal of Ethnobiology 34:401-424.
Sen, A. 1999. Development as Freedom. Random House, New York, NY.

Swiderska, K. 2006. Protecting Traditional Knowledge: A Framework Based on Customary Laws and Bio-Cultural Heritage Sustainable Agriculture, Biodiversity and Livelihoods Programme. Paper presented at the International Conference on Endogenous Development and Bio-Cultural Diversity. Geneva, Switzerland. Available at: http:// pubs.iied.org/pdfs/G01069.pdf. Accessed on January 5, 2014.

Wabaseemoong Wild Rice Project. 2015. This 9 Minute Video is from Last Year, Thank You to the People Who Produced It Valeria and Anastasia, and the People in the Video, Thank You Iian [Facebook post]. Available at: https://www.facebook.com/ Wabaseemoong-Wild-Rice-Project$674480755940362 /$ ?fref $=$ ts. Accessed on December 23, 2016.

Wolverton, S. 2013. Ethnobiology 5: Interdisciplinarity in an Era of Rapid Environmental Change. Ethnobiology Letters 4:21-25. DOI:10.14237/ ebl.4.2013.11.

Wyndham, F. S., D. Lepofsky, and S. Tiffany. 2011. Taking Stock in Ethnobiology: Where Do We Come From? What Are We? Where Are We Going? Journal of Ethnobiology 31:110-127. DOI:10.2993/0278-077131.1.110. 